\title{
Fortuna e atribulações das comédias de Jorge Ferreira de Vasconcelos
}

\author{
Silvina Pereira
}

\begin{abstract}
J. M. De Bujanda em "Censura portuguesa y censura española", oferece uma reflexão sobre a Inquisição, a censura e controlo dos livros. Em particular, trata da censura preventiva. Diz o investigador castelhano, que a censura é uma das actividades principais das três Inquisições modernas: a romana e as peninsulares, espanhola e portuguesa. A partir dos Índices dos livros proibidos, e fazendo-se o estudo comparativo entre as duas censuras, a espanhola e a portuguesa, pode detectarse que há convergências e divergências quanto a diversos aspectos: a organização, a orientação da censura prévia, a impressão e a censura posterior.
\end{abstract}

Em Espanha, a censura prévia era uma atribuição exclusiva do Conselho Real, correspondendo ao Estado, enquanto a censura das obras impressas, ficava no âmbito do Santo Ofício, entidade que publicava os catálogos dos livros proibidos e expurgados e vigiava pela sua aplicação.

Em Portugal, a primeira intervenção da Coroa Portuguesa em matéria de censura remonta a uma lei de Agosto de 1451, condenando ao fogo alguns escritos. À excepção deste caso, são raros os vestígios da existência de uma censura literária em Portugal anteriores à fundação da Inquisição. Um exemplo da censura régia está no privilégio concedido a Baltazar Dias em 1537, onde se pode ler que as obras devem ser examinadas e aprovadas, antes da sua impressão, pelo maestro Pedro Margalho. Mas "[a] partir da nomeação do Cardeal Infante D. Henrique como Inquisidor Geral a 22 de Junho de 1539, a Inquisição exerce plenamente a censura anterior e ulterior à impressão" (De Bujanda 2007: 449, tradução nossa).

Em 1540, já o Cardeal D. Henrique estabelecia com a participação dos três dominicanos, F. Bobadilha, A. Salier e C. Valbuena, uma organização estável para o exercício da censura inquisitória, que passou a ocupar-se de uma forma regular da censura anterior à impressão, conforme se infere, segundo De Bujanda, pelo número significativo de livros impressos com a aprovação explícita do Santo Ofício. Em 1547, no primeiro Índice de livros proibidos, o Inquisidor Geral obrigava a um exame anterior à impressão, por parte da Santa Inquisição, disposição que se repetirá no Índice de 1561. Também a Inquisição portuguesa exercia uma censura sobre a vida intelectual nas universidades, quer através das teses dos alunos (nos Índices também constam teses), quer quanto ao teor das aulas ministradas pelos professores, que circulavam em cadernos manuscritos.

Em 1564, a Inquisição portuguesa aceita as normas romanas, nomeadamente a regra $\mathrm{X}$, que obriga a que todo o escrito tenha, antes de ser impresso, a aprovação do
Bispo ou do Inquisidor Geral. Ficámos, deste modo, com duas censuras obrigatórias: a episcopal e a inquisitória, embora prevalecendo a segunda. Em 1570, são retirados os inquisidores locais a favor da aprovação da Inquisição central, até que a situação do ponto de vista legal se altera completamente, quando em 1576 é promulgada uma lei por D. Sebastião, estabelecendo que, para além das duas anteriores, teria que haver também uma censura civil, 0 Desembargo do Paço, perfazendo, deste modo, uma tripla censura: inquisitória, episcopal e civil, sendo que será a censura inquisitória que irá prevalecer e ser predominante durante muito tempo.

É, pois, diferente a maneira como foi exercida a censura preventiva nos dois países. Em Espanha, a Inquisição está à margem de toda a intervenção antes da impressão, enquanto em Portugal ela funcionou como um órgão por excelência de censura prévia até à impressão, com repercussões sobre a edição impressa e condicionando a natureza dos escritos publicados

J. M. De Bujanda assinala o limitado material disponivel sobre as características e efeitos da censura portuguesa, lembrando que nas obras profanas a censura, na sua forma preventiva, não assinalava o que suprimia nem o porquê, nem dava indicação sobre os critérios dos censores, tal como na licença de impressão não se vislumbrava o que era corrigido ou expurgado, ficando no silêncio dos deuses as matérias intervencionadas, de forma a permitir a concessão da licença. Esta intervenção desautoriza ao mesmo tempo as edições não expurgadas. Neste periodo de trabalhos secretos, a que António José Saraiva chama de fase secreta da aprovação dos livros, são propostos pelo revisor os termos e correcções a introduzir para a permissão de impressão.

Qual o impacto sobre a produção intelectual nacional destes três filtros e até que ponto o resultado oferece textos alterados? Qual a influência da censura prévia na impressão, na quantidade e na qualidade das obras publicadas? I. S. Révah vê na censura prévia a causa da não publicação de muitos manuscritos que reuniam condições para publicação.

Independentemente do número de manuscritos recusados e mutilados, a que só uma catalogação apropriada (fundos de bibliotecas e dos arquivos portugueses) poderá dar uma resposta parcial, o que não oferece dúvida é que a censura anterior funcionou como efeito de dissuasão sobre os autores, já que estes estariam cientes que a obra não passaria, quer pelas normas da Inquisição romana, quer pelo Santo Ofício português. Esta 




situação, difícil de avaliar, terá dado lugar a uma autocensura, com consequências reais na criação e no eclodir de ideias novas. Em La censure inquisitoriale portugaise au XVI siècle, o mesmo Révah afirmava categórico que, "em matéria de censura dos livros, Portugal ocupou, a partir de 1551,

uma posição de vanguarda entre os países católicos. A experiência acumulada pelos censores portugueses foi utilizada, muitas vezes com algum atraso, pelos outros censores católicos" (Révah 1960: 8, tradução nossa).

Esta constatação, subscrita por Raul Rêgo - "Triste glória esta de nos pormos à frente da repressão intelectual" (Rêgo 1982: 45) - e António José Saraiva, é questionada por De Bujanda, que oferece um ponto de vista um pouco diferente. Em sua opinião, relacionando os diferentes Catálogos, verifica-se sobretudo uma grande receptividade, por parte dos portugueses, aos congéneres romanos e europeus, ou seja, "Os inquisidores portugueses não são os autores, mas antes os compiladores da maioria das censuras". 0 número das proibições é muito reduzido.

Embora seja reconhecivel a influência reciproca entre as actividades de censura nas duas inquisições ibéricas, não há documentação que permita perceber as razões das convergências e das divergências dos Índices ibéricos. Esta reciprocidade de influências não impede, contudo, a existência de diferenças importantes entre as duas inquisições. A principal divergência encontra-se na atitude dos inquisidores em relação aos escritos espirituais e aos escritos de literatura profana: a portuguesa, menos crispada em relação aos escritos de devoção, mas muito mais intransigente que a espanhola, em relação aos escritos de cunho literário "que contêm passagens ousadas do ponto de vista moral".

Para J. M. De Bujanda, talvez estas diferenças se expliquem pelas figuras dos próprios Inquisidores Gerais:

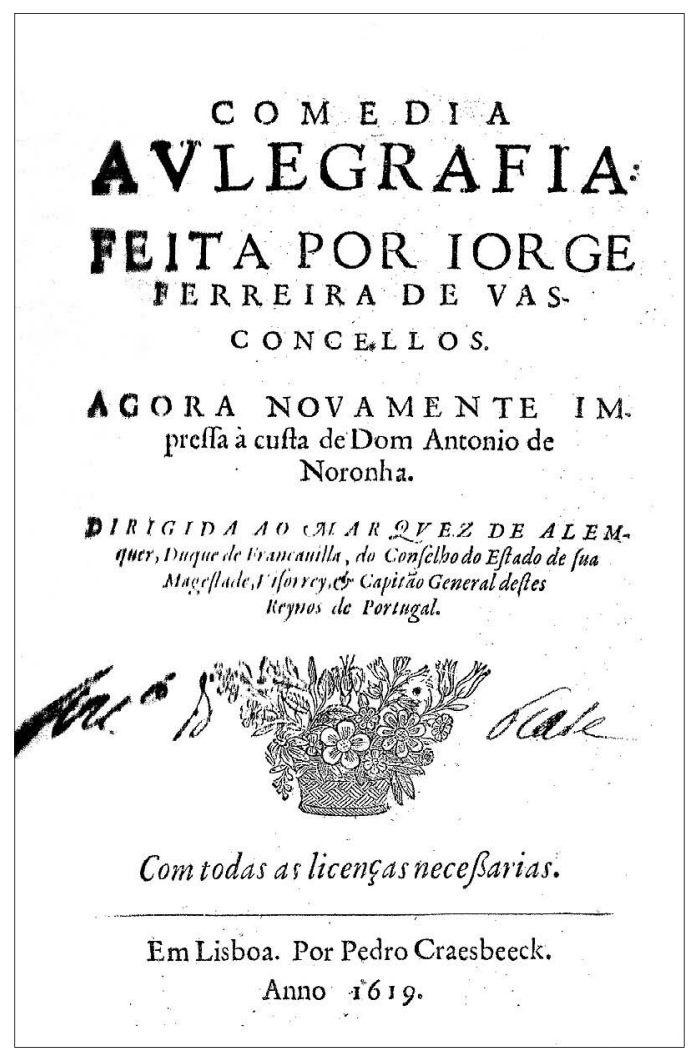

Comedia Eufrosina de Jorge Ferreira de Vasconcelos (Coimbra, João de Barreyra, 1555).

Comedia Aulegrafia, de Jorge Ferreira de Vasconcelos (Lisboa, Pedro Craesbeeck, 1619)
0 Cardeal D. Henrique, inquisidor durante quarenta anos (de 1539 a 1579), e Don Fernando de Valdés, durante vinte anos (de 1547 a 1568). D. Henrique, homem austero, não partilhava a desconfiança de Valdés em relação aos escritos espirituais. Muitas obras espirituais proibidas pela inquisição espanhola circulavam em Portugal, algumas até impressas com licença da Inquisição lusitana, ao ponto de bibliotecas portuguesas conservarem exemplares raros condenados pela Inquisição espanhola, que constituem hoje uma fonte importante de estudo para a história cultural e religiosa dos dois paises:

Contrariamente aos escritos literários que têm uma conotação obscena, D. Henrique e a Inquisição portuguesa adoptam plenamente a regra VII do índice do Concilio de Trento e proibem certos clássicos da literatura castelhana e portuguesa como a Celestina, de Fernando de Rojas, Eufrosina, de Jorge Ferreira de Vasconcelos, Menina e Moça, de Bernardim Ribeiro, e Ropica pnefma, de João [de] Barros. (De Bujanda 2007: 457, tradução minha)

Vejamos agora o impacto da acção da censura na obra impressa de Jorge Ferreira de Vasconcelos. Das obras atribuidas ao comediógrafo, somente as três comédias, Eufrosina, Ulysippo, Aulegrafia, e o Memorial, são hoje conhecidas. Aceitando a existência da edição de Os triunfos de Sagramor, Jorge Ferreira de Vasconcelos ter-se-á estreado no prelo como escritor no ano de 1554. Entretanto a Eufrosina, cuja data de composição Asensio remete para os anos de 1542/43, circulou anónima e manuscrita até 1555, ano em que saiu no prelo de João de Barreira. Grandes foram os triunfos da Comédia Eufrosina. Quatro impressões quinhentistas, duas em Coimbra (1555 e 1560) e duas em Évora (1561 e 1566), a que se seguiu a primeira edição da Ulysippo antes de 1561 e o Memorial em 1567. 
Comedia Ulyssippo de Jorge Ferreira de Vasconcelos (Lisboa, Pedro

Craesbeeck, 1618)

Conversão de

Hermógenes,

Mestre da Lourinhã

antigo retábulo da lgreja do Convento de Palmela, finais do primeiro quarte do século XVI, Museu Nacional de Arte Antiga.

Pelo ritmo da saida das obras, é plausivel considerar-se esse período para a edição princeps da Ulysippo.

Ou mesmo oito, caso uma 5. impressão da Eufrosina, em 1570, se

vier a confirma (cf. Asensio 1986: 181).
Entre a década de 1550 e 1560, com o Sagramor, a reedição dupla da Eufrosina (4) a edição da Ulysippo (1556-59) ${ }^{1}$ e a do Memorial (1567), temos ao todo, pelo menos, sete impressões. ${ }^{2}$ Sem dúvida, como diríamos hoje, um grande sucesso editorial.

Mas este êxito assinalável foi contrariado pelas sucessivas entradas nos Índices: 1561, 1564, 1581 e 1624, um facto com consequências nefastas para a futura circulação e recepção da obra.

Remetendo somente para a obra dramática, a primeira edição da Ulysippo desapareceu, a Eufrosina saiu de circulação e a Aulegrafia não chegaria a ser impressa, muito embora estivesse pronta, como dirá mais tarde D. António de Noronha, na dupla condição de genro do autor e de editor. Hoje, pelo cotejo da edição póstuma da Aulegrafia com o manuscrito de Madrid, é possível afirmar que também esta edição seiscentista se encontra censurada.

Vejamos então o que nas comédias de Jorge Ferreira de Vasconcelos incomodava os censores. Comecemos pela Eufrosina. Num artigo que publiquei em 2008, "Ventos de Espanha", a propósito da tradução castelhana da comédia, foi possivel demonstrar como a edição "emendada" de Francisco Rodrigues Lobo, em 1616, censura e adapta o texto de Jorge Ferreira de Vasconcelos, expurgando-o de diferentes maneiras: alterações em matérias políticas, casuísticas, eróticas, religiosas, astrológicas, linguísticas, morais, bem como omissões, transformando o texto, através da mudanças radicais de sentido e até por desfigurações com aspectos anedóticos.

Quanto à Ulysippo, Eugenio Asensio sublinha que "[...] foi tão exemplar a condenação que nem um exemplar se salvou e desconhecemos até a data da edição princeps" (Asensio 1951: LXXV, tradução minha), pelo que, com a "segunda impressão apurada, e correcta de alguns erros da primeira", apenas podemos conjecturar que a expurgação seguiu critérios similares, ainda que no texto Advertência ao Leitor que acompanha a comédia, seja referido que "Vaivos a desejada Ulysippo emendada \& inteira", e que somente foi mudada a condição da personagem Costança Dornelas de "beata", no original, para "viúva".

Igualmente a Aulegrafia não se salvou da censura. Quando me deparei pela primeira vez com uma cópia manuscrita desta comédia, existente na Real Biblioteca de Palácio, em Madrid, foi fácil verificar, grosso modo, que esta era uma versão diferente da edição impressa seiscentista. José Camões, num artigo publicado em 2008, sobre esta versão manuscrita, aponta também uma série de variantes da edição de 1619, podendo constatar-se que a intervenção censória incide sobre os mesmos aspectos já acima mencionados para a Eufrosina na versão de Francisco Lobo: anti-castelhanismo, linguagem obscena, carga erótica de algumas observações amorosas, aparentes desvios da doutrina, alusões a personagens bíblicas e a santos. Este manuscrito é, pois, mais um testemunho da terrivel censura que se abateu sobre a obra de Vasconcelos. Vem revelar
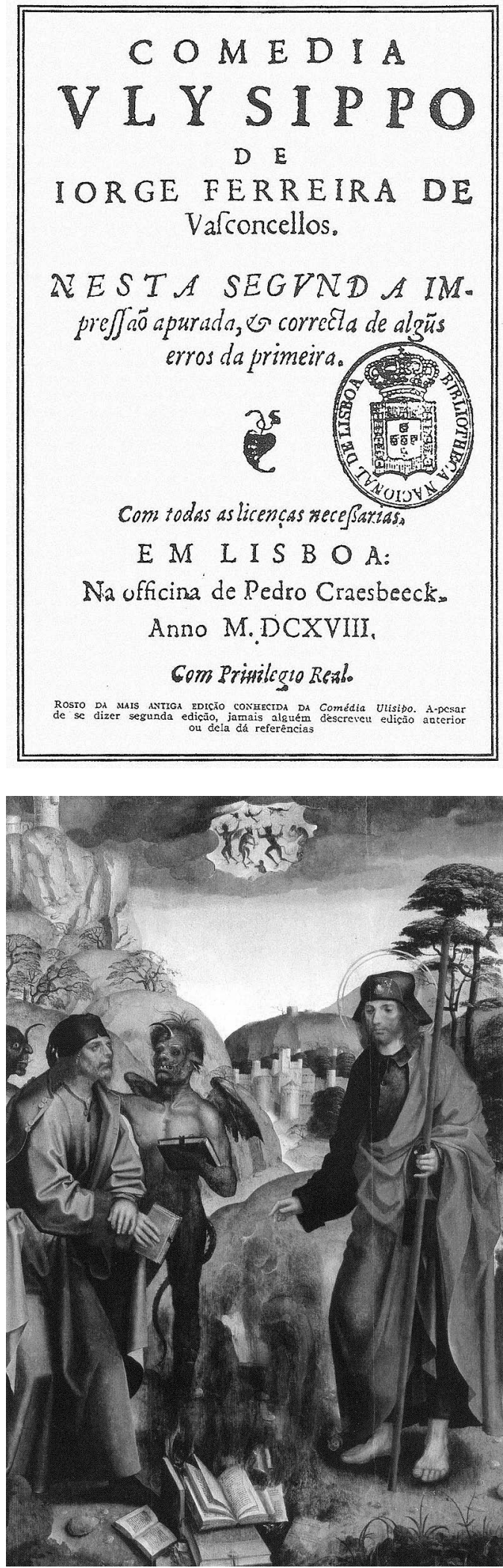

que a impressão de 1619 conta com intervenções no texto, como supressões e alterações, quer de editores ou tipógrafos, quer de censores, que não terão sido muito brandos.

Deste modo, todas as comédias de Jorge Ferreira de Vasconcelos terão acabado por ser censuradas, já que todas as edições seiscentistas - Eufrosina de 1616, Ulysippo de 1618 e Aulegrafia de 1619 - surgem expurgadas. 

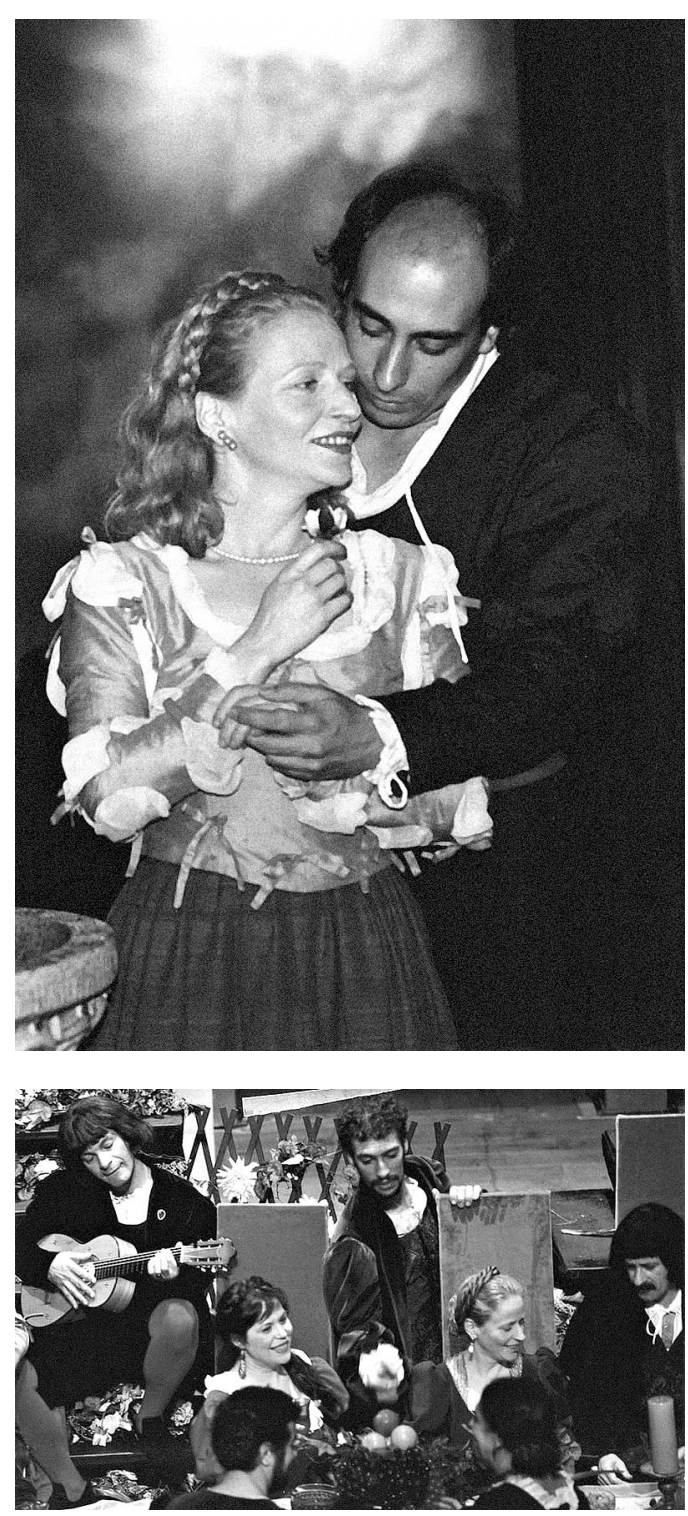

Sobre a influência da censura nas comédias de Jorge Ferreira de Vasconcelos, e para concluir, verifica-se que a acção da Inquisição, essa "instituição de mil faces, um espaço de cruzamento de poderes políticos e religiosos, económicos e culturais" (Barreto / Mourão 2007: 5), através da acção dos seus censores, quase fez desaparecer da nossa memória o seu nome e a sua obra, com a entrada das suas comédias nos Índices portugueses do século XVI e XVII.

Nas suas comédias, encontram-se matérias que não poderiam respirar em tempo e circunstâncias já tão contrárias a uma "subtileza erasmiana que advoga, sobretudo, a liberdade pensamento" (Rêgo 1982: 12). Jorge Ferreira de Vasconcelos começou por atravessar uma época marcada por um pensamento libertário e luminoso. Mas com o avançar do século XVI, a atmosfera foi mudando. Neste contexto adverso, "os erasmistas inquietam-se e começam a ser inquietados" (Ibidem: 14). A tensão entre tolerância e intolerância foi-se agudizando, acabando por prevalecer, segundo o parecer de António José Saraiva, o "ataque ao próprio espirito que anima o impulso humanista".

E hoje? Hoje não há nenhuma censura institucional, nem da Igreja nem do Estado. No entanto, será que não se encontram hoje formas subtis de controlo e/ou censura sob a égide de "critérios editoriais"? A verdade é que não se pode publicar tudo (e as comédias de Vasconcelos continuam à espera de publicação), invocando as "leis de mercado", ou a evocação de "critérios de qualidade artística", que podem conduzir a outras tantas formas sofisticadas de censura prévia, ainda que a palavra censura esteja arredada e que, como é óbvio, não se assume como tal.

\section{Referências bibliográficas}

ASENSIO, Eugenio (1951), Edição, prólogo e notas a Comedia Eufrosina, de Jorge Ferreira de Vasconcelos, texto da edição princeps de 1555 com as variantes de 1561 e 1566, Madrid, CSIC - Instituto Miguel de Cervantes. ASENSIO, Eugenio (1986), "Para una nueva edición critica e comentada de la Comedia Eufrosina de Jorge Ferreira de Vasconcelos", in Critique Textuelle Portugaise: Actes de Colloque - Paris, 20-24 Octobre 1981, Paris, Fondation Calouste Gulbenkian / Centre Culturel Portugais, pp. $179-184$.

BARRETO, Luis Filipe / MOURÃO, José Augusto et al. (Drgs) (2007), Inquisição portuguesa: Tempo, razão e circunstância, Lisboa e São Paulo.

CAMÕES, José (2008), "Um outro rascunho da vida cortesã̃: Uma cópia inédita da Aulegrafia de Jorge Ferreira de Vasconcelos", Românica, n. ${ }^{17}$, Lisboa, FLUL, pp. 169-196.

DE BUJANDA, J. M. (2007), "Censura portuguesa y censura española", in Inquisição portuguesa: Tempo, razão e circunstância, Lisboa e São Paulo, Prefácio, pp. 447-457.

PEREIRA, Silvina (2007), "Ventos de Espanha. La Eufrosina de Jorge Ferreira de Vasconcelos. Uma tradução espanhola pouco conhecida", in Maria João Brilhante e Manuela Carvalho (org.), Teatro e tradução: Palcos de encontro, Act 15, Lisboa, Campo das Letras, pp. 369-393.

RÊGO, Raul (1982), Os indices expurgatórios e a cultura portuguesa, col. Biblioteca Breve, vol. 61, Lisboa, ICLP.

RÉVAH, Israel Salvator (1960), La Censure Inquisitoriale Portugaise au XVI siècle, vol. I, Lisboa, Instituto da Alta Cultura.
Comedia Eufrosina, de Jorge Ferreira de Vasconcelos, enc. Silvina Pereira, Teatro Maizum, Igreja do Convento dos Inglesinhos, 1995 (Isabel Fernandes e Júlio Martin).

\section{Comedia Ulyssippo,} de Jorge Ferreira de Vasconcelos, enc. Silvina Pereira, Teatro Maizum, Teatro da Trindade, 1997 (de frente, Augusto Portela, Silvina Pereira, Amilcar Azenha, Isabel Fernandes, João Maria Pinto; de costas, Rui Sérgio e Esmeralda Veloso). 